\title{
OS DIREITOS DOS JOVENS NO ESTATUTO DA JUVENTUDE À LUZ DO PRINCÍPIO DA DIGNIDADE DA PESSOA HUMANA
}

\section{RIGHTS OF YOUTH IN YOUTH STATUS IN THE LIGHT OF THE PRINCIPLE OF HUMAN DIGNITY}

\author{
${ }^{1}$ Eduardo Fin De Figueiredo \\ ${ }^{2}$ Wilson Kredens da Paz
}

\section{RESUMO}

Este artigo apresenta um estudo acerca dos direitos dos jovens no Estatuto da Juventude à luz do Princípio da Dignidade da Pessoa Humana. Aborda, como objetivo geral, a importância de efetivar o direitos dos jovens e a necessidade de implementar políticas públicas efetivas para toda a juventude, especificamente, traz a conceituação de dignidade da pessoa humana e as principais características do princípio constitucional, apresenta no contexto brasileiro o que levou a promulgação do Estatuto da Juventude e comentários sobre a preocupação com a efetividade da lei promulgada, estuda, de forma crítica a possibilidade de modificar a atual realidade social brasileira.

Palavras-chave: Direitos dos jovens, Estatuto da juventude, princípio da dignidade da pessoa humana

\begin{abstract}
This article presents a study on the rights of young people in the Youth Statute in light of the Principle of Human Dignity . Addresses, as a general objective , the importance of carrying out the rights of young people and the need to implement effective public policies for all youth , especially, of constitutional principle, it presents in the Brazilian context which led to the enactment of the Youth Statute and comments on the concern about the effectiveness of enacted law studies, critically the possibility of modifying the current Brazilian social reality.
\end{abstract}

Keywords: Rights of youth, Statute of youth, Principle of human dignity

\footnotetext{
${ }^{1}$ Mestrando em Direito Empresarial e Cidadania pelo Centro Universitário Curitiba - UNICURITIBA, Paraná, ( Brasil). Presidente da OAB Jovem da Subseção de Pato Branco/PR. É advogado e Sócio-Proprietário do Escritório de Advocacia - Figueiredo Advocacia. Professor Universitário na Faculdade Mater Dei em Pato Branco, Paraná. Email: tutortreinamento@gmail.com

${ }^{2}$ Especialização LLM em Direito Empresarial Aplicado pela Federação das Indústrias do Estado do Paraná - FIEP, Curitiba, (Brasil). Experiência na área de Direito Empresarial, Bancário e Consumidor. E-mail: tutortreinamento@ gmail.com
} 


\section{INTRODUÇÃO}

Os direitos dos jovens no Estatuto da Juventude, Lei ${ }^{\circ} 12.852$ de 05 de agosto de 2013, está previsto no capítulo II, dos direitos dos jovens, e, faz parte do título I, dos direitos e das políticas públicas de juventude. Entretanto, conforme será demonstrado no presente trabalho os direitos dos jovens estão presentes em outras letras de lei vigentes no ordenamento jurídico brasileiro, como é o caso do Estatuto da Criança e do Adolescente e da própria Constituição Federal de 1988.

É importante ressaltar que em que pese o Estatuto da Juventude ter sido promulgado no ano de 2013, seu estudo se iniciou 10 anos antes, essa demora para se referendar a lei é vista como um atraso, visto que o bônus demográfico brasileiro de 2003 para 2013 foi de aproximadamente 15 milhões de jovens, passando de 35 milhões em 2003 para 50 milhões em 2013. Ou seja, 15 milhões de jovens deixaram de usufruir o que dispõe o Estatuto da Juventude, mesmo que outras políticas públicas de juventude tenham sido implementadas nesse período.

Em síntese, por meio da promulgação do Estatuto da Juventude é que o Estado brasileiro buscou reconhecer e efetivar o papel estratégico da juventude no desenvolvimento do país, até porque a juventude representa $1 / 3$ da população nacional, sendo a principal fonte de mão de obra, o estatuto visa apontar os direitos que devem ser garantidos de acordo com a especificidade da população.

No presente trabalho será elaborada uma reflexão da atual realidade da população jovem brasileira e um estudo crítico sobre os direitos dos jovens no Estatuto da Juventude à luz do princípio da dignidade da pessoa humana, visto que o mencionado princípio constitucional é o mais copioso do ordenamento jurídico, vez que é reputado como fundante do Estado Democrático de Direito, sendo afirmado já no primeiro artigo da Constituição Federal, abrangendo todos os demais princípios, dada a sua universalidade.

Com essa visão da problemática inicial, pretende-se, pois, abordar, como objetivo geral, a importância de se efetivar o direitos dos jovens e a necessidade de se implementar políticas públicas efetivas a toda a juventude, especificamente, (a) num primeiro momento traz a conceituação de dignidade da pessoa humana, um pouco de histórico e as principais características do princípio constitucional, (b) apresenta no contexto brasileiro o que levou a promulgação do Estatuto da Juventude, com um aporte temporal da sucessão que desencadeou o referendo do estatuto, e comentários sobre a preocupação com a efetividade da lei promulgada e seus principais objetivos para a garantia e efetivação dos direitos dos jovens (c) estuda, de forma crítica, os direitos dos jovens no estatuto da juventude à luz do princípio da dignidade da 
pessoa humana, na garantia dos direitos fundamentais e na possibilidade de modificar a atual realidade social brasileira.

O estudo se justifica de diferentes maneiras, pelo simples fato da população jovem brasileira representar $1 / 3$ de toda a população, pela contribuição acadêmica acerca do tema relevante e interdisciplinar que, embora atual, ainda possui um campo vasto para pesquisa dos seus aspectos jurídicos, os quais, naturalmente, não serão exauridos com o presente trabalho, em geral, para a reflexão de juristas e sociólogos que possuem interesse em se aprofundar ao tema proposto, para tanto será realizada pesquisa essencialmente bibliográfica.

Para fins didáticos, o artigo será dividido em três tópicos, os quais observarão e estão diretamente relacionados aos objetivos específicos anteriormente delineados. No primeiro tópico será abordado, em linhas gerais, o princípio da dignidade da pessoa humana, seu conceito e principais características, no segundo tópico uma reflexão sobre a promulgação do Estatuto da Juventude e uma exposição cronológica dos fatos que resultaram no referendo da Lei, e, por fim, no terceiro tópico o tema principal do artigo que são os direitos dos jovens no Estatuto da Juventude à luz do princípio da dignidade da pessoa humana.

\section{BREVES CONSIDERAÇÕES SOBRE O PRINCÍPIO DA DIGNIDADE DA PESSOA HUMANA}

A dignidade humana nada mais é que um direito fundamental do cidadão, entretanto, seu conceito pode discrepar se analisado em diferentes documentos jurídicos. Contudo, não se trata de algo contemporâneo, vez que surgiu com o cristianismo e, em seguida, foi expressamente abarcada na defesa dos direitos dos seres humanos, da dignidade no Código de Hamurabi, bem como no Código de Manu. (KUMAGAI; MARTA, 2015).

A noção de dignidade de pessoa humana é flexível, visto que varia de acordo com o tempo e espaço, "sofrendo impacto da história e da cultura de cada povo, bem como de circunstâncias políticas e ideológicas”. Assim, muitos autores defendem a concepção de que conceituá-la nada mais é que "ilusão", em que pese ser indispensável para a argumentação e aplicação do ordenamento jurídico. (BARROSO, 2015).

Para Kant, a dignidade é o valor daquilo que não se pode estimar o preço, assim, considera-a infungível. É um adjetivo intrínseco do ser humano moral, que age de acordo com os preceitos éticos, portanto, a dignidade é absolutamente inerente a autonomia da pessoa, e, justamente por esse fato, somente os humanos são dotados de dignidade. (KANT, 2004. p. 52). 
Noutro lanço, após a segunda guerra mundial a dignidade da pessoa humana passou a ser um valor imperioso para a implantação de um estado democrático de direito. Todavia, a dignidade foi enaltecida como princípio fundamental e serviu de base para os demais princípios, bem como para as normas constitucionais e infraconstitucionais. E, em vista disso, as constituições de diversos países incorporaram, expressamente, em seus textos, tal direito fundamental.

Para corroborar com o aludido acima, faz-se conveniente enaltecer o entendimento do doutrinador Luís Roberto Barroso:

\begin{abstract}
A dignidade da pessoa humana, na sua concepção contemporânea, tem origem religiosa, bíblica: o homem feito à imagem e semelhança de Deus. Com o Iluminismo e a centralidade do homem, ela migra para a filosofia, tendo por fundamento a razão, a capacidade de valoração moral e autodeterminação do indivíduo. Ao longo do século $\mathrm{XX}$, ela se torna um objetivo político, um fim a ser buscado pelo Estado e pela sociedade. Após a $2^{\circ}$ Guerra Mundial, a idéia de dignidade humana migra paulatinamente para o mundo jurídico, em razão de dois movimentos. O primeiro foi o surgimento de uma cultura pós-positivista, que reaproximou o positivismo normativista. $\mathrm{O}$ segundo constituiu na inclusão da dignidade da pessoa humana em um conceito jurídico, a dificuldade presente está em dar a ela um conteúdo mínimo, que a torne uma categoria operacional e útil, tanto na prática doméstica de cada país quanto no discurso transnacional. (BARROSO, 2015).
\end{abstract}

No Brasil, de acordo com Cleber Francisco Alves a Constituição do Império de 1824 já se referia aos direitos fundamentais, tais como: liberdade, propriedade e segurança individual. Outrora, não havia menção expressa da dignidade da pessoa humana, apenas enaltecia os princípios da igualdade e da legalidade. Por outro lado, em 1934, foi incorporado, pela primeira vez, ao texto constitucional brasileiro "a todos existência digna". (ALVEZ, 2001. p. 126).

Atualmente, o princípio da dignidade da pessoa humana é o mais copioso do ordenamento jurídico, vez que é reputado como "fundante do Estado Democrático de Direito, sendo afirmado já no primeiro artigo da Constituição Federal”. Por corolário, abrange todos os demais princípios, dada a sua universalidade. (DIAS, 2009. p. 61).

A dignidade da pessoa humana é a veracidade inerente à pessoa, com pretensão de respeito e compreensão das demais. O estado deve asseverar os direitos fundamentais, ao passo que iniba qualquer limitação que menospreze as garantias basilares dos seres humanos. Nesse sentido, a corroborar com o explanado, faz-se assaz elucidar o entendimento do professor Alexandre de Moraes:

O direito á vida privada, à intimidade, à honra, à imagem, entre outros, aparece como consequiência imediata da consagração da dignidade da pessoa humana como fundamento da República Federativa do Brasil. Esse fundamento afasta a idéia de 
predomínio das concepções transpessoalistas de Estado e Nação, em detrimento da liberdade individual. [...] o princípio fundamental consagrado pela Constituição Federal da dignidade da pessoa humana apresenta-se em uma dupla concepção. Primeiramente, prevê um direito individual protetivo, seja em relação ao próprio Estado, seja em relação aos demais indivíduos. Em segundo lugar, estabelece verdadeiro dever fundamental de tratamento igualitário dos próprios semelhantes. (MORAES, 2007. p. 61).

A constituição federal vigente no direito brasileiro foi promulgada com o fito de assegurar os interesses individuais, bem como os da coletividade, defendendo e efetivando os direitos fundamentais dos mesmos. Não obstante, inseriu, expressamente, em seu art. $1^{\circ}$, inciso III, o princípio da dignidade da pessoa humana, com relevância crucial.

A referida Carta Magna de 1988 enobrece com nitidez o prestígio da dignidade da pessoa humana, como já aludido no decorrer da aclaração do presente tópico. Assim, pode-se enfatizar que está é a Constituição Federal mais democrática que foi promulgada no Brasil, vez que preconiza os direitos sociais, individuais e coletivos.

$\mathrm{O}$ ordenamento jurídico exige que o indivíduo respeite a dignidade do próximo, bem como exige que respeite a sua própria dignidade, com o fito de manter a ordem e garantir a custódia dos direitos fundamentais basilares. Assim, "a Declaração Universal dos Direitos Humanos, assinada pelo Brasil, reconhece a dignidade como inerente a todos os membros da família humana e como fundamento da liberdade, da justiça e da paz do mundo”. (MORAES, 2007. p. 61).

Destarte, a dignidade da pessoa humana é fundamento jurídico para a defesa e efetivação dos direitos fundamentais. Por se tratar de um princípio, ora norma jurídica, indica valores e os fins a serem realizados, uma vez que tem como principal característica a flexibilidade, sendo assim, molda-se a cada caso concreto.

Os direitos dos jovens, como de qualquer outro ser humano, estão intimamente ligados à dignidade da pessoa humana, pois o princípio da dignidade da pessoa humana é fundante do Estado Democrático de Direito, abrangendo os demais princípios, dada a sua universalidade. (DIAS, 2009. p. 61).

Contudo, Wanderson Lago Vaz e Clayton Reis entendem que:

Com o advento da Constituição Federal, o princípio da dignidade humana passou a ter importância ímpar. É a força motriz de todo nosso ordenamento jurídico. É através dele que irradiam todos os demais princípios. A dignidade da pessoa humana constituise em uma conquista que o ser humano realizou no decorrer dos tempos, derivada de uma razão ético-jurídica contra a crueldade e as atrocidades praticadas pelos próprios humanos, uns contra os outros, em sua trajetória histórica. Mas, é preciso ressaltar que existem determinadas situações em que são permitidas a limitação ao princípio da dignidade humana, apesar do seu caráter absoluto e intangível concedido por nossa 
Constituição Federal. Nesses casos, cave ao judiciário ou legislador decidir a questão da colisão entre os direitos fundamentais - direito á dignidade e o direito à vida. No Brasil, como é adotado a relativização do principio da dignidade da pessoa humana, diante de tal colisão, prevalece o direito á vida. (LAGO VAZ, 2015).

Dada à importância suprema da dignidade da pessoa humana, esta foi incorporada pelo ordenamento jurídico vigente, como princípio axial, uma vez que se trata de valor moral essencial para manutenção dos estados democráticos de direito.

Por derradeiro, como anteriormente mencionado, não se pode olvidar que o princípio debatido incide diretamente nas relações dos jovens, e na proteção dos seus direitos, assim, revela-se inequívoca a repercussão do princípio em tela na configuração e efetivação constitucional dos direitos dos jovens à luz da dignidade da pessoa humana. Desta feita, passese a sapiência de tal temática, em relação, especificamente, aos direitos dos jovens. (FACHIN; PIANOVSKI, 2015).

\section{A PROMULGAÇÃO DO ESTATUTO DA JUVENTUDE}

Conforme valioso estudo elaborado pela professora Mirlene Severo, doutora em sociologia, verificou-se que na década noventa, acentuou-se a desigualdade social em razão da globalização neoliberal, com algumas consequências sociais marcantes, como a intensificação do desemprego, a falta de projetos culturais, a precarização da educação, a concentração de renda e o empobrecimento da juventude. Tais consequências sociais levaram à criação do atual Estatuto da juventude, entretanto, a autora destaca alguns pontos cronológicos anteriores à promulgação do Estatuto que merecem destaque, no ano de 2003 se deu início a uma sistematização do Estatuto da Juventude, em 2004 houve a proposta de direitos civis aos jovens, por meio do projeto de Lei $n^{\circ}$ 4.529/04, na Comissão Especial de Juventude na Câmara dos Deputados, e ainda, no ano de 2005 ocorreu a criação da Secretaria Nacional da Juventude e a instalação do Conselho Nacional da Juventude. (SEVERO, 2016).

Por mais que a sistematização do Estatuto da Juventude tenha iniciado no ano de 2003, sua promulgação se deu somente no ano de 2013, 10 anos se passaram e nesse intervalo de tempo foi criado em 2005 pela Lei ${ }^{\circ} 11.129$ o Conselho Nacional de Juventude (Conjuve), que também instituiu a Secretaria Nacional de Juventude, vinculada à Secretaria-Geral da Presidência da República (SNJ/SG/PR), e o Programa Nacional de Inclusão de Jovens (Projovem), todos mecanismos para dar efetividade aos direitos dos jovens e criar políticas públicas eficientes em prol da juventude. 
O Conselho Nacional de Juventude (Conjuve), especificamente, tem entre suas atribuições, a de formular e propor diretrizes voltadas para as políticas públicas de juventude, desenvolver estudos e pesquisas sobre a realidade socioeconômica dos jovens e promover o intercâmbio entre as organizações juvenis nacionais e internacionais. O Conjuve é composto por $1 / 3$ de representantes do poder público e $2 / 3$ da sociedade civil, contando, ao todo, com 60 membros, sendo 20 do governo federal e 40 da sociedade civil, essa composição foi estruturada para que as ações sejam articuladas em todas as esferas governamentais (federal, estadual e municipal), com o objetivo de contribuir para que a política juvenil se transforme, de fato, no Brasil, em uma política de Estado. (JUVENTUDE, 2016).

O Estatuto da Juventude, propriamente dito e como já mencionado, foi instituído pela Lei ${ }^{\circ} 12.852 / 13$, sendo promulgado, assim, tão somente, no ano de 2013, tratando, em linhas gerais, sobre os direitos dos jovens e os princípios e diretrizes das políticas públicas da juventude e ainda, sobre o Sistema Nacional de Juventude que também é conhecido por SINAJUVE. É importante ressaltar que por meio do Estatuto da Juventude é que o Estado brasileiro buscou reconhecer o papel estratégico da juventude no desenvolvimento do país, apontando os direitos que devem ser garantidos de acordo com a especificidade da população. (GOVERNO, 2016).

Nesse mesmo sentido a professor Léia Comar Riva, explica em seu artigo "Estatuto da Juventude e a Garantia dos Direitos Fundamentais" que:

\footnotetext{
O Estatuto da Juventude, composto por 48 artigos e divididos em dois títulos, determina, sobre os direitos e as políticas públicas (arts. $1^{\circ}$ a 38 ) e o Sistema Nacional de Juventude (Sinajuve) (arts. 39 a 48) e atribui, respectivamente, nos artigos 41 a 44, competências à União, tais como: "formular e coordenar a execução da Política Nacional de Juventude"; "coordenar e manter o Sinajuve" e "elaborar o Plano Nacional de Políticas de Juventude, em parceria com os Estados, o Distrito Federal, os Municípios e a sociedade, em especial a juventude". Em meio às competências atribuídas aos Estados, aos Municípios e, cumulativamente, ao Distrito Federal está a de coordenar, nos respectivos âmbitos, o Sinajuve. (GOVERNO, 2016).
}

Em síntese, pode-se dizer que o Estatuto da Juventude foi promulgado para dar efetividade aos direitos dos jovens, que mesmo anteriormente previstos (Constituição Federal de 1988 e Estatuto da Criança e do Adolescente) eram deixados de lado, buscou-se dar voz aos jovens, promovendo um novo conjunto de leis para garantir o desenvolvimento do país pelos jovens, diferenciando cada vez mais as o tratamento das parcelas da população (criança, adolescente, jovens e idosos) e apostando no potencial da juventude para superar a crise social. 
Como dito anteriormente, com a intensificação do desemprego, falta de projetos culturais, precarização da educação, empobrecimento da juventude, viu-se a necessidade de implementação de políticas públicas e efetivação dos direitos dos jovens, dai surgiu o Estatuto da Juventude, como instrumento de "solucionar" os dados alarmantes que recaem sobre a população jovem brasileira. Além disso, um dos objetivos do EJV é que os jovens voltem a ser protagonistas no cenário político brasileiro, motivados por um senso de dever e ética com as causas sociais. (MEDEIROS, 2016).

Tanto o Conjuve, a SNJ/SG/PR, o Projovem e o próprio Estatuto da Juventude tem por objetivo comum que as políticas juvenis se transforme em uma políticas de Estado, levando em conta a opinião do público alvo (jovens), que por meio da sua participação, venha assegurar a todos os jovens uma educação acessível e de qualidade, formação profissional adequada, oportunidades dignas de trabalho e renda, alternativas de lazer saudável e aconselhamentos sobre reprodução e saúde sexual. Assim, o que se quer assegurar é que independente de quem esteja no governo as políticas públicas para efetivação dos direitos dos jovens sempre estejam presentes na agenda governamental, acabando com os estereótipos negativos associados à juventude. (MEDEIROS, 2016).

Em que pese o Estatuto da Juventude de forma ampla poder ser considerado um grande avanço para a efetivação dos direitos dos jovens, considerando que o platô de população jovem brasileira teve seu início em 2003 e o projeto de Lei do Estatuto iniciou a tramitação em 2004, sendo referendado somente em 2013, evidencia-se que o Estatuto da Juventude já nasceu com um atraso de 10 anos, se for levar em consideração o bônus demográfico brasileiro de 2003 (aproximadamente 35 milhões de jovens no Brasil) para 2013 (aproximadamente 51 milhões de jovens no Brasil). (ARAUJO, 2016).

Além disso, como será demonstrado posteriormente em que pese a bonita letra de lei presente no Estatuto da Juventude a realidade dos jovens no Brasil não é nada glamorosa, mesmo com a implementação das políticas públicas os dados em relação aos jovens são alarmantes e merecem atenção governamental, até porque, como dito, a população jovem representa $1 / 3$ da população do Brasil, e é a principal mão de obra para a busca do desenvolvimento econômico e social da nação.

No tocante à preocupação com a efetividade do Estatuto da Juventude, importante mencionar os autores Igor Mateus Batista e Renan Bandeirante de Araújo, em seu artigo Juventude, Trabalho e Educação: Um estudo crítico do Estatuto da Juventude: 


\begin{abstract}
Na lei, vemos uma preocupação importante com a proteção do jovem no trabalho. Porém é preciso destacar que no cenário da produção destrutiva, o desemprego em massa e a exclusão social, atingem principalmente a juventude. E ainda é preciso considerar que, conforme Alves (2014), a juventude compõe o "precariado, que é a camada média do proletariado urbano constituída por jovensadultos altamente escolarizados com inserção precária nas relações de trabalho e vida social” (p. 189). Levando em conta tais informações, observa-se que os jovens sofrem tanto com o desemprego quanto com as subcondições de trabalho precário. Contudo, percebemos que o Estatuto visa garantir direitos, avanços, mas que não alteram a estrutura do sistema, apenas visa amenizar os impactos do capitalismo, ou seja, cooptar as juventudes conforme analisa Sanfelice (2013) “insinua-se consertar o que na verdade é inconsertável” (p. 139). Com isso percebemos que o conteúdo do Estatuto, em seus traços gerais, nos remete a um constante reformismo. Ou seja, tentar colocar o capitalismo como humanitário, mas sem promover mudanças 3765 estruturais ou alterações substanciais capazes de modificar as bases do sistema promotora da exploração e das injustiças.
\end{abstract}

Assim, a grande preocupação da promulgação do Estatuto da Juventude com o atraso de 10 anos é de que a lei seja apenas um marco histórico para a sociedade brasileira fundada em desigualdade, sem a efetividade que os jovens realmente necessitam, deixando de ter um efeito prático para reverter os dados negativos dos jovens no Brasil em relação ao desemprego, renda, mortalidade e educação.

Sem uma resposta sobre o futuro brasileiro e indo de encontro a todos esses preocupantes dados brasileiros em relação aos jovens, o objetivo principal do Estatuto da Juventude é somar com o Estatuto da Criança e do Adolescente, à medida que pretende criar, ainda que com atraso, mecanismos para assegurar o respeito à dignidade humana e a autonomia do jovem, visando contribuir efetivamente para a garantia dos direitos fundamentais constitucionalmente elencados, tentando traçar um caminho possível para garantir a dignidade àqueles que serão responsáveis pelo futuro da nação brasileira. (RIVA, 2016).

\title{
3. OS DIREITOS DOS JOVENS NO ESTATUTO DA JUVENTUDE À LUZ DO PRINCÍPIO DA DIGNIDADE DA PESSOA HUMANA
}

Os direitos dos jovens estão previstos no capítulo II, intitulado "dos direitos dos jovens" e faz parte do título I "dos direitos e das políticas públicas de juventude" da Lei no 12.852, de 05 de agosto de 2013, que dispõe sobre o Estatuto da Juventude. No presente trabalho o que se busca é fazer uma análise de um estudo crítico da real efetividade dos direitos dos jovens na sociedade brasileira à luz do princípio da dignidade da pessoa humana.

Primeiramente, é importante trazer alguns dados para ter noção e se situar no momento dos jovens no Brasil e da realidade de $1 / 3$ da população nacional, segundo dados do próprio governo federal (2014) o Brasil tem cerca de 50 milhões de jovens com idade entre 15 e 29 
anos (DEMBOSKI BÚRIGO, 2016). Além disso, o governo explica que, muitos desses 50 milhões de jovens demonstram determinação em assegurar seus direitos, por meio das políticas públicas governamentais, o que o governo não explica são os dados alarmantes envolvendo jovens, mesmo com as políticas públicas implementadas. (BRASIL, 2016).

Ainda conforme declina o governo federal com a instituição do Estatuto da Juventude em 2013, buscaram-se políticas públicas para garantir os direitos dos jovens, caminhando para que a juventude seja incorporada como política de Estado, no combate às desigualdades. (BRASIL, 2016). Ocorre que, os dados envolvendo os jovens com idade entre 15 e 29 anos no Brasil não são muito favoráveis, de acordo com o Mapa da Violência de 2015, 58\% das pessoas que morreram no país em decorrência do disparo de algum tipo de arma de fogo eram jovens de 15 a 29 anos. (BRASIL, 2016).

Além disso, conforme dados do IBGE (2013), dos cerca de 50 milhões de jovens entre 15 e 29 anos, 20,3\% não trabalham nem estudam, conhecidos como a geração "não-nem" e apenas uma em cada dez mulheres da população situada nessa faixa etária com pelo menos um filho, continua estudando. Em 2013 o Brasil tinha mais jovens negros de 18 a 24 anos no ensino médio do que no ensino superior. (BRASIL, 2016).

Considerando apenas os jovens brasileiros entre 20 e 24 anos, os dados são ainda piores, segundo a OCDE - Organização para a Cooperação e o Desenvolvimento Econômico (2015), o Brasil tem o maior índice de jovens que não estão estudando, os dados mostram que no Brasil 76\% dos jovens entre 20 e 24 anos estão longe dos estudos, isso reflete o fracasso das políticas públicas governamentais, pois a educação é deixada de lado para que os jovens consigam ter alguma renda para ajudar sua família, estagnando o desenvolvimento tanto econômico como social do país. (ON LINE, 2016).

Ou seja, pela simples leitura dos dados trazidos fica evidente o fato que levou a promulgação do Estatuto da Juventude, ocorre que, mesmo com a sua promulgação e com a implementação das atuais políticas públicas os dados ainda são alarmantes. Sem dúvida há necessidade de transformar as atuais políticas públicas, para que se tornem políticas públicas de Estado, para garantir e efetivar os direitos dos jovens em observância ao princípio da dignidade da pessoa humana.

A simples aprovação de novas Leis se mostrou ineficaz no atual cenário, importante mencionar que inúmeros direitos dos jovens já estavam previstos na carta magna em sentido amplo, mesmo anteriormente a aprovação dos estatutos, o que falta é dar efetividade aos direitos e não novas disposições em papel. No ordenamento pátrio temos outros exemplos no mesmo sentido, como é o caso do Estatuto da Criança e do Adolescente datado de 1990, que após 25 
anos ainda caminha em passos lentos para modificar drasticamente a realidade das crianças e dos adolescentes no Brasil.

Além disso, em nível constitucional, é de suma importância mencionar que a Emenda Constitucional $n^{\circ} 65$ de 13 de julho de 2010, aprovada, assim, antes do Estatuto da Juventude, atribuiu aos jovens brasileiros uma proteção mais específica ao dar nova redação ao artigo 227 da Constituição Federal, tendo como prioridade absoluta o direito a dignidade do jovem. Aqui, ressalte-se que tanto na Constituição Federal, como no Estatuto da Criança e do Adolescente e no próprio Estatuto da Juventude, há menção, como direito do jovem a vida digna, à dignidade, dai a importância de se estudar os direitos dos jovens à luz do princípio da dignidade da pessoa humana.

De nada adianta uma lei extremamente vantajosa e com inúmeros benefícios aos jovens, se o governo não consegue dar meios para que a lei seja efetivamente cumprida, essa movimentação legislativa tem que possuir um norte, que é o respeito ao princípio da dignidade da pessoa humana. Entretanto, como já mencionado, verifica-se que as atuais políticas públicas se traduzem insuficientes para a diminuição da desigualdade e a melhora da qualidade de vida dos jovens garantida constitucionalmente. (ON LINE, 2016).

$\mathrm{Na}$ verdade, diante dos alarmantes índices apresentados, o governo federal deveria primar por programas efetivos que elevassem o índice de alfabetização e de escolaridade dos jovens, o que consequentemente resultaria em melhor inserção no mercado de trabalho. O que não se pode admitir é ter como resposta aos indesejáveis índices a promulgação de Leis sem os mecanismos para dar efetividade e ações somente emergenciais e compensatórias aos jovens socialmente mais vulneráveis, é preciso também, abrir espaço para a incorporação de abordagens específicas no interior das demandas universais, implementando políticas públicas de Estado. (COELHO DE ANDRADE, 2016).

Em relação a efetivação dos direitos dos jovens a Professora Mariane Pires Castagna, em sua dissertação para obtenção do Título de "Mestre em Direito", com o tema "O direito à profissionalização do jovem brasileiro: uma análise à luz do princípio da dignidade da pessoa humana" explica que:

Percebe-se que para a efetivação dos direitos dos jovens, crianças e adolescentes pontuados alguns deveres a serem observados pela família, sociedade, comunidade e nos casos dos jovens pelo Poder Público. Para a juventude os deveres são mais no sentido de fomentar e incentivar as ações dos jovens que inclusive podem participar na formulação e na avaliação de políticas sociais específicas. A formação educacional dos jovens já é mais orientada para a inserção no mercado de trabalho, incentivandose formação profissional. Já para crianças e adolescentes os deveres são de caráter eminentemente protetivo condizente com a sua condição de indivíduos em desenvolvimento. (CASTAGNA, 2016). 
No que diz respeito especificamente aos direitos dos jovens elencados no Estatuto da Juventude, estão dispostos no capítulo II, e as seções I, II e III tratam respectivamente: do Direito à Cidadania, à Participação Social e Política e à Representação Juvenil, do Direito à Educação e do Direito à Profissionalização e à Renda, lembrando que a dignidade da pessoa humana deve ser o norte desses direitos, até porque é valor, norma e princípio de todo o ordenamento jurídico brasileiro, inclusive princípio orientador do Estatuto da Juventude.

No tocante ao Direito à Cidadania, à Participação Social e Política e à Representação Juvenil, vale citar o artigo $4^{\circ}$ do Estatuto da Juventude, que dispõe que o jovem tem direito à participação social e política e na formulação, execução e avaliação das políticas públicas de juventude. Esse artigo é uma grande conquista a toda a juventude, a essência do diploma legal, consiste no reconhecimento do jovem como sujeito político, sujeito de direitos, reconhece o lugar do jovem na sociedade, que se contrapõe ao discurso vendido de que o jovem está em transformação e não pode mudar a sociedade. (CARRANO, 2016).

Quanto ao Direito à Educação, em que pese a previsão específica no EJV, é um direito constitucional disposto no artigo 205 da Constituição Federal de 1988, o qual dispõe que a educação é direito de todos e dever do Estado e da Família, devendo ser promovido e incentivado pela sociedade, visando o desenvolvimento da pessoa e seu preparo para o exercício da cidadania e sua qualificação para o trabalho, já no artigo $7^{\circ}$ do Estatuto da Juventude, dispõe que o jovem tem direito à educação de qualidade, com a garantia de educação básica, obrigatória e gratuita, inclusive aos que a ela não tiveram acesso na idade adequada. O que se observa, é que o artigo do EJV especifica o direito previsto constitucionalmente, entretanto, é bom lembrar, de que adianta a letra da lei, se o governo federal não investe em educação, a lei se torna inócua diante da falta de investimentos e da precariedade do ensino. (MAIA LIMA, 2016).

Por fim, quando ao Direito à Profissionalização ao Trabalho e á Renda, previsto no artigo 14 do Estatuto da Juventude, observa-se que é essencial para que o jovem conquiste sua autonomia, a partir do momento que o jovem acessa o mercado do trabalho em busca de renda, mas sempre diretamente ligado com o direito a educação e a continuidade do estudo. Nesse aspecto importante mencionar que o Direito a Profissionalização ao Trabalho e a Renda, além de estar disposto expressamente no artigo 227 da Constituição Federal, vai de encontro com a necessidade da mão de obra jovem para alavancar a economia do país.

Ou seja, o Estatuto da Juventude promulgado em 2013, vem para somar com as demais disposições legais já vigentes, pretendendo criar mecanismos para assegurar o respeito a 
dignidade da pessoa humana, diminuindo as desigualdades e buscando a aceitação da juventude como parte da diversidade da condição humana. Além disso, o EJV visa reafirmar e contribuir para a garantia dos direitos fundamentais constitucionais. (RIVA, 2016).

Os números dos jovens no Brasil, não são nada favoráveis, mesmo com a instituição do Estatuto da Juventude, os jovens ainda vêm passando por inúmeras dificuldades, sem representatividade, sem acesso à educação ou acesso a uma educação deficitária, o que influencia diretamente no direito ao trabalho e a profissionalização. Não há uma solução pronta para efetivar os direitos dos jovens, no entanto, deve-se pensar em políticas públicas que combinem projetos e ações que assegurem igualdade de direitos da cidadania, valorizando a diversidade juvenil por meio de ações afirmativas e respostas às demandas que dizem respeito à atual condição do jovem.

Por fim, é de suma importância frisar, que os jovens são muito mais do que números, são a expressão mais concreta da sociedade e por isso devem estar inseridos em programas que possam tirá-los da situação de pobreza, miséria, e de desigualdade para que possam também contribuir na busca da igualdade e evolução não só social mas também econômica. (SEVERO, 2016).

\section{CONSIDERAÇÕES FINAIS}

Diante da pesquisa realizada foi possível ter uma noção de que os jovens no Brasil representam 1/3 da população nacional, com aproximadamente 51 milhões de jovens, sendo que a realidade dessa fatia da população não está nada favorável, segundo alguns dados apresentados. Conforme consta no Mapa da Violência de 2015, 58\% das pessoas que morreram em decorrência de algum tipo de arma de fogo eram jovens, 20,3\% dos jovens no Brasil não trabalham nem estudam e ainda, 76\% dos jovens entre 20 e 24 anos estão longe dos estudos.

Diante da importância da população jovem no Brasil, não somente por representar 1/3 de toda a nação, muito mais do que isso, por ser o futuro do Brasil e a principal fonte de mão de obra, para evolução social e econômica é que se pensou em uma legislação específica, que no caso é a Lei $\mathrm{n}^{\mathrm{o}}$ 12.852/13 denominada Estatuto da Juventude. Importante ressaltar que o Estatuto da Juventude já nasceu com um atraso de 10 anos, sendo que seus estudos começaram em 2003, quando o Brasil possuía 25 milhões de jovens a menos, todo esse bônus populacional não foi abarcado com a promulgação da referida Lei.

O estudo do Estatuto da Juventude à luz do princípio da dignidade da pessoa humana se faz importante e necessário, por inúmeros fatores, entre eles o fato do princípio constitucional 
ser o princípio orientador do Estatuto da Juventude, sendo que o princípio da dignidade da pessoa humana deve ser o norte para a análise e aplicação dos direitos dos jovens, até porque, está presente tanto na Constituição Federal, como no Estatuto da Criança e do Adolescente e no próprio Estatuto da Juventude.

Em relação ao princípio da dignidade da pessoa humana, pode-se concluir que é o princípio mais copioso no ordenamento jurídico brasileiro, vez que é reputado como fundante do Estado Democrático de Direito, abrangendo todos os demais princípios, dada a sua universalidade. Além disso, a dignidade da pessoa humana é a veracidade inerente à pessoa, com pretensão de respeito e compreensão das demais, devendo o estado asseverar os direitos fundamentais, inibindo qualquer limitação as garantias dos seres humanos.

No presente artigo o que se buscou apresentar foi a atual situação dos jovens no Brasil e o que levou a promulgação do Estatuto da Juventude, demonstrando e explicando os direitos inerentes aos jovens no Estatuto da Juventude e na legislação brasileira em geral e a necessidade de mudanças nos mecanismos atuais para dar efetividade ao disposto na lei, com políticas públicas que possam reverter os dados alarmantes no tocante aos jovens, futuro de toda uma nação.

Nesse aspecto, a conclusão que se chega é que o Estatuto da Juventude foi promulgado para dar efetividade aos direitos dos jovens, que mesmo anteriormente previstos (Constituição Federal de 1988 e Estatuto da Criança e do Adolescente) eram deixados de lado. Além disso, um dos objetivos do EJV é que os jovens voltem a ser protagonistas no cenário político brasileiro, motivados por um senso de dever e ética com as causas sociais, apostando no potencial da juventude para superar a crise econômica e social.

Entretanto, a grande preocupação da promulgação do Estatuto da Juventude com o atraso de 10 anos é de que a Lei seja apenas um marco histórico para a sociedade brasileira fundada em desigualdade, sem a efetividade que os jovens realmente necessitam, deixando de ter um efeito prático para reverter os dados negativos dos jovens no Brasil em relação ao desemprego, renda, mortalidade e educação.

Assim, contata-se que a simples aprovação de uma Lei específica aos jovens não é a solução de todos os problemas da juventude, alguns dos direitos dos jovens já estavam previstos na Carta Magna (Emenda Constitucional $n^{\circ}$ 65) em sentido amplo, mesmo anteriormente a aprovação do Estatuto da Juventude, e nem assim se conseguiram dar efetividade aos direitos dos jovens. De nada adianta uma lei extremamente vantajosa e com inúmeros benefícios aos jovens, se o governo não consegue dar meios para que a Lei seja efetivamente cumprida, essa movimentação legislativa tem que possuir um norte, que é o respeito ao princípio da dignidade 
da pessoa humana, entretanto, verifica-se que as atuais políticas públicas se traduzem insuficientes para a diminuição da desigualdade e a melhora da qualidade de vida dos jovens.

$\mathrm{Na}$ verdade, diante dos alarmantes índices apresentados, o governo federal deveria primar por programas efetivos que elevassem o índice de alfabetização e de escolaridade dos jovens, o que consequentemente resultaria em melhor inserção no mercado de trabalho. O que não se pode admitir é ter como resposta aos indesejáveis índices a promulgação de Leis sem os mecanismos para dar efetividade e ações somente emergenciais e compensatórias aos jovens socialmente mais vulneráveis, é preciso também, abrir espaço para a incorporação de abordagens específicas no interior das demandas universais, implementando políticas públicas de Estado.

Portanto, pelo que foi estudado, conclui-se que os números dos jovens no Brasil, não são nada favoráveis, mesmo com a instituição do Estatuto da Juventude os jovens ainda vem passando por inúmeras dificuldades, sem representatividade, sem acesso à educação ou acesso a uma educação deficitária, o que influencia diretamente no direito ao trabalho e a profissionalização. Não há uma solução pronta para efetivar os direitos dos jovens, no entanto, não podemos perder as esperanças, somos brasileiros e não desistimos nunca, deve-se pensar em políticas públicas que combinem projetos e ações que assegurem igualdade de direitos da cidadania, valorizando a diversidade juvenil por meio de ações afirmativas e respostas às demandas que dizem respeito à atual condição do jovem.

Só assim, com políticas públicas que combinem projetos e ações que assegurem igualdade de direitos de cidadania, onde seja valorizada a diversidade juvenil por meio de ações afirmativas, sempre em atenção ao princípio da dignidade da pessoa humana, é que irá conseguir uma efetividade quanto aos direitos dos jovens e uma evolução tanto social como econômica.

\section{REFERÊNCIAS BIBLIOGRÁFICAS}

ABRAMO, Helena Wendel, BRANCO, Pedro Paulo Martoni (orgs.). Retratos da Juventude brasileira: análises da pesquisa nacional. São Paulo: Fundação Perseu Abramo, 2005.

ABRAMO, Helena Wendel. Considerações sobre a tematização social da juventude no Brasil. Revista Brasileira de Educação, no 5/6, maio-dez, 1997. (Número especial sobre Juventude e Contemporaneidade). Acesso em 20 dez 2015. 
ALVEZ, Cleber Francisco. O princípio Constitucional da Dignidade da Pessoa Humana: O enfoque da Doutrina Social da Igreja. Rio de Janeiro: Renovar, 2001. p. 126.

ARAUJO, Renan Bandeirante de e BATISTA, Igor Mateus. Juventude, Trabalho e Educação: Um estudo crítico do Estatuto da Juventude. Disponível em: <http://www.cih.uem.br/anais/2015/trabalhos/1532.pdf>. Acesso em: 25 jan 2016.

BARROSO, Luís Barroso. A dignidade da pessoa humana no direito constitucional contemporâneo: natureza jurídica, conteúdos mínimos e critérios de aplicação. Disponível em: <http://www.luisrobertobarroso.com.br/wp-content/themes/LRB/pdf/a_dignidade_da_pessoa_humana_no_direito_constitucional.pdf>. Acesso em: $20 \mathrm{dez} 2015$.

BRANCO, Pedro Paulo Martoni, ABRAMO, Helena (organizadores.) Retratos da Juventude Brasileira: Análises de uma Pesquisa Nacional. São Paulo: Fundação Perseu Abramo, 2005.

BRASIL. Constituição da República Federativa do Brasil. 17. ed. Brasília: Câmara dos Deputados, 2001.

BRASIL, Portal. CIDADANIA E JUSTIÇA - Estatuto da Juventude passa o vigorar no País. Disponível em: <http://www.brasil.gov.br/cidadania-e-justica/2013/08/estatuto-da-juventude-passa-a-vigorar-no-pais>. Acesso em: 02 fev 2016.

BRASIL, Portal. CIDADANIA E JUSTIÇA - Políticas públicas buscam garantir direitos dos jovens. Disponível em: <http://www.brasil.gov.br/cidadania-e-justica/2014/04/politicaspublicas-buscam-garantir-direitos-dos-jovens>. Acesso em: 02 fev 2016.

BARRIENTOS-PARRA, Jorge. O Estatuto da Juventude. Revista de Informação Legislativa. v. 41, n. 163, 2004.

CARRANO, Paulo. A participação social e política de jovens no Brasil: considerações sobre estudos recentes. Disponível em: $<$ http://osocialemquestao.ser.puc-rio.br/media/OSocial27_Carrano1.pdf> Acesso em 02 fev 2016. 
CASTAGNA, Mariane Pires. O direito à profissionalização do jovem brasileiro: uma análise à luz do princípio da dignidade da pessoa humana. Disponível em: <https://repositorio.ufsc.br/xmlui/bitstream/handle/123456789/94815/293903.pdf?sequence= 1\&isAllowed=y> Acesso em 02 fev 2016.

COELHO DE ANDRADE, Carla. Juventude e políticas públicas no Brasil. Disponível em: $<$ http://www.ipea.gov.br/desafios/index.php?option=com_content\&view=article\&id=1094: catid=28\&Itemid=23> Acesso em: 10 fev 2016.

CONJUVE. O que é?. Disponível em: http://juventude.gov.br/conjuve. Acesso em: 20 dez 2015.

CONSTANZI, Rogério Nagamine. Trabalho decente e juventude no Brasil. Brasília: OIT, 2009.

CORREIA JÚNIOR, C.O.F.. O estatuto da juventude: Um estudo sobre os limites e possibilidades da nova lei para as políticas públicas de juventude. $2013.73 \mathrm{f}$. Trabalho de Conclusão de Curso (Bacharel em Serviço Social) - Universidade Federal Fluminense, Pólo Universitário Rio das Ostras, 2013.

CURY, Beto. Os muitos desafios da política nacional de juventude. In: AVRITZER, Leonardo [org.]. Experiências nacionais de participação social. São Paulo: Cortez, 2009. (Coleção Democracia Participativa).

DEMBOSKI BÚRIGO, Beatriz; EUGENIO, Jessica Daminelli; SOUZA, Ismael Francisco de. O Programa Nacional de Inclusão de Jovens (Projovem) como política pública específica para jovens. Rio Grande, XV, n. 106, nov 2012. Disponível em: <http://www.ambitojuridico.com.br/site/index.php/site/livros_gratis/abrebanner.php?n_link=revista_artigos_leitur a\&artigo_id=12050\&revista_caderno=12> Acesso em: 02 fev 2016.

DIAS, Maria Berenice. Manual de Direito das Famílias. 5.ed. São Paulo: Revista dos Tribunais. 2009. p. 61. 
FACHIN, Luiz Edson; PIANOVSKI, Carlos Eduardo. A Dignidade da pessoa humana no direito contemporâneo: uma contribuição à crítica da raiz dogmática do neopositivismo constitucional. Disponível em: <http://www.anima-opet.com.br/pdf/anima5Conselheiros/Luiz-Edson-Fachin.pdf>. Acesso em: $18 \mathrm{dez} 2015$.

KANT, Immanuel. Fundamentação da metafísica dos costumes, tradução de Leopoldo Holzbach, São Paulo: Martin Claret, 2004. p. 52.

KUMAGAI, Cibele; MARTA, Taís Nader. Princípio da dignidade da pessoa humana. In: Âmbito Jurídico, Rio Grande, XIII, n. 77, jun 2010. Disponível em: <http://www.ambitojuridico.com.br/site/index.php?n_link=revista_artigos_leitura\&artigo_id=7830>. Acesso em: $20 \operatorname{dez} 2015$.

LAGO VAZ, Wanderson; REIS, Clayton. Dignidade da pessoa humana. In: Revista Jurídica Cesumar, jun 2007. Disponível em: <http://periodicos.unicesumar.edu.br/index.php/revjuridica/article/view/522>. Acesso em: 20 $\operatorname{dez} 2015$.

MAIA LIMA, Antonia Lucy. Educação de Jovens e Adultos: Políticas Públicas no Município de Pinhais. Disponível em: $<$ http://www.ppge.ufpr.br/teses/M13_ANTONIA\%20Lucy\%20Lima\%20Maia.pdf> Acesso em: 01 fev 2016.

MEDEIROS, Alexsandro Melo. Políticas Públicas. Disponível em: <http://www.portalconscienciapolitica.com.br/ci\%C3\%AAncia-politica/politicas-publicas/>. Acesso em: 18 jan 2016.

MEDEIROS, Alexsandro Melo. Políticas Públicas de Juventude. Disponível em: < http://www.portalconscienciapolitica.com.br/ci\%C3\%AAncia-politica/politicaspublicas/juventude/>. Acesso em: 18 jan 2016.

MORAES, Alexandre de. Constituição do Brasil interpretada e legislação constitucional. 7.ed. São Paulo: Atlas, 2007. p. 61. 
OLIVEIRA, Luciano. Não fale do código de Hamurábi. A pesquisa sócio-jurídica na pósgraduação em direito. Disponível em: <http://www.uniceub.br/media/180293/Texto_IX.pdf.>. Acesso em: 12 set. 2015.

PAIS, José Machado. Culturas juvenis. Lisboa: Imprensa Nacional, Casa da Moeda, 1993.

RIVA, Léia Comar. Estatuto da Juventude e a Garantia dos Direitos Fundamentais. Disponível em:

http://www.lex.com.br/doutrina_24801997_ESTATUTO_DA_JUVENTUDE_E_A_GARAN TIA_DOS_DIREITOS_FUNDAMENTAIS.aspx>.Acesso em: 22 jan 2016.

SEVERO, Mirlene Fátima Simões Wexell. O Estatuto da Juventude no Brasil (2004-2013): Relações de poder, disputas por hegemonia e direitos humanos. Jundiai, Paco Editorial: 2015.

SEVERO, Mirlene Simões. Direitos Sociais dos Jovens no Brasil: Concepções e Experiências. Disponível em: < http://seer.fclar.unesp.br/seguranca/article/view/3696/3456>. Acesso em: 19 jan 2016.

SPOSITO, Marília Pontes; CARRANO, Paulo. Juventude e políticas públicas no Brasil. Disponível em: <http://www.scielo.br/pdf/rbedu/n24/n24a03> Acesso em: 10 fev 2016.

VANNUCHI, Paulo, NOVAES, Regina. Juventude e Sociedade: Trabalho, Educação, Cultura e Participação. São Paulo: Fundação Perseu Abramo, 2004. 